\section{FULLY INTEGRATED IMAGING SOLUTIONS}

Underpinning the successful introduction of digital equipment is the ability to seamlessly integrate digital hardware with your clinical records. To this end, Software of Excellence has the ideal solution.

With over 20 years' experience in UK dentistry, Software of Excellence is renowned throughout the industry with its market-leading EXACT $^{\text {тм }}$ practice management system. This foundation gives Software of Excellence the knowledge and experience to provide digital imaging solutions through EXAMINE ${ }^{\text {PRO }}$.

EXAMINE $^{\text {PRO }}$ places all images into a single imaging database regardless of their source, meaning you can combine equipment from a range of manufacturers to best suit your needs. All images can be viewed as an integral part of the patient chart, meaning you can see all the restorative information as well as the location and age of all films and images.

Software of Excellence's digital imaging solutions set the industry standard for high quality imaging and X-ray technology. With quick and easy transmission to a computer screen, and compatibility with EXACT $^{\mathrm{Tm}}$, Software of Excellence offer digital imaging hardware and software that is responsive,

\title{
GROUNDBREAKING EQUIPMENT SOLUTION
}

Discover a new generation of magnification equipment with the Dentaloscope 2D Extra-oral Video Magnification System (EVMS). Available from trusted surgery design and equipment specialist Clark Dental, the Dentaloscope is an outstanding solution to the limitations of alternative magnification and illumina-

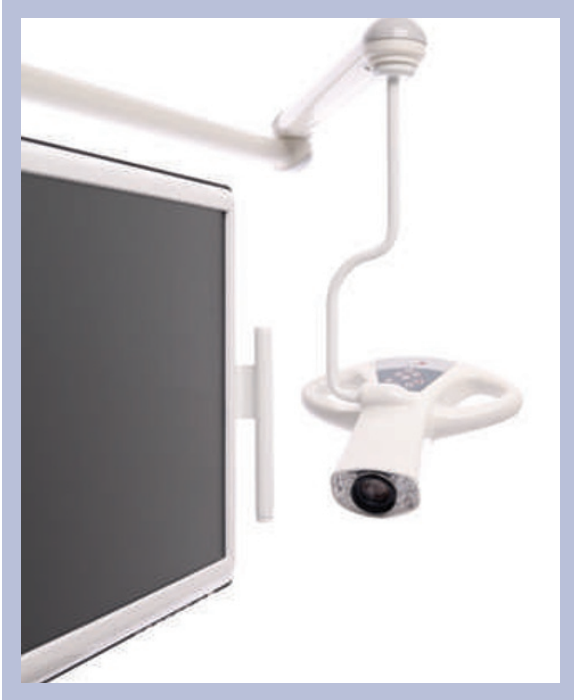

tion equipment. When mounted with the VELscope, this innovative system even lets you provide an oral cancer screening service.

The 19" screen and easily positioned scope arm helps the user find the perfect view of the treatment site and ensure that correct posture is maintained throughout, even the most demanding procedures. Boasting the highest resolution digital colour CCD camera chip currently available, the Dentaloscope's high specification features also include $25 \times$ optical zoom, hands-free image capture and 50x digital magnification to facilitate accurate diagnosis and effective communication with patients.

The Clark Dental team provides a comprehensive service, including installation, training and aftercare to suit any budget, enabling you to make the most of the Dentaloscope's outstanding range of applications.

Reader response number 63

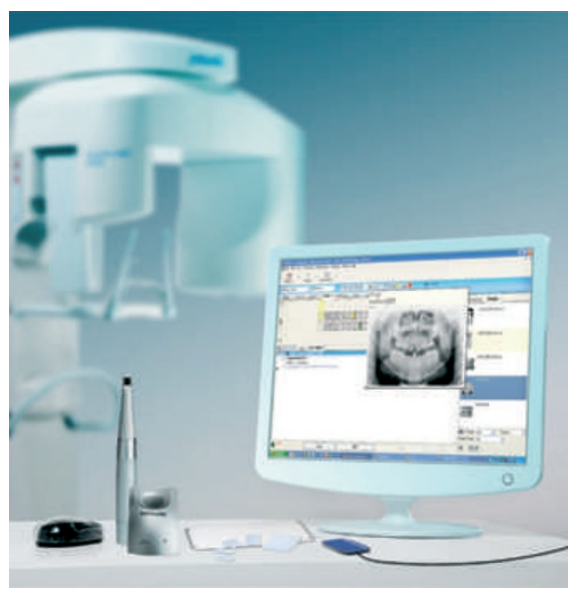

accurate and highly effective.

Reader response number 62

\section{THE LATEST IN LED TECHNOLOGY}

GC has developed the G-Light, a curing light that utilises the very latest in LED technology.

Many new dental materials do not contain the light initiator camphorquinine and therefore cannot be cured by conventional 'blue light' LEDs. The G-Light's blue and violet LEDs give you two different wavelength peaks at the same time, ensuring optimum curing of all of your VLC materials.

With a high intensity, narrow spectrum of light, the G-Light emits the maximum amount of light energy right to the tip of the handpiece. This re-chargeable light can be used over 400 times for 10 seconds without any reduction in intensity. The constant light energy guarantees efficient and deep curing every time.

The lightweight, ergonomically designed, cordless G-Light can be set to a range of practical curing times including 5, 10 and 20 second intervals, as well as continuous mode to suit your individual requirements. It is simply designed and manufactured to an exceptionally high standard.

\section{Reader response number 65}

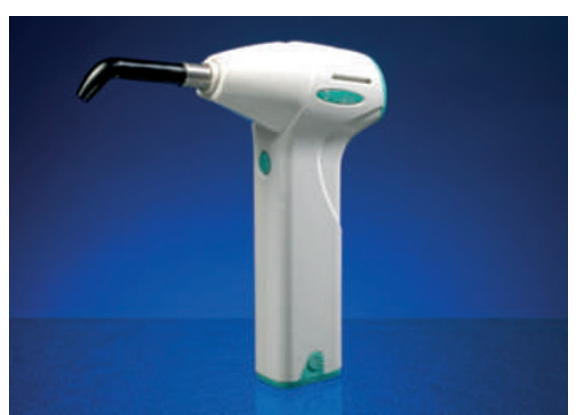

\section{CONVINCE CHILDREN TO ENJOY BRUSHING THEIR TEETH}

Flipper is the fun way to encourage children to use their toothbrush regularly. A toothbrush holder that attaches to bathroom mirrors and tiles with a suction cup, Flipper comes in five different animal characters from the Wild Family range, all of which will bring a smile to tired faces in the morning and at bedtime.
As the child takes hold of the toothbrush handle and pulls, the cover will simply flip open, and when the brush is returned Flipper will close on itself, keeping the toothbrush tidy and protecting the bristles from cross contamination of bacteria.

Reader response number 64 